Article

\title{
Effects of Velocity Profiles on Measuring Accuracy of Transit-Time Ultrasonic Flowmeter
}

\author{
Hui Zhang ${ }^{1,2}$, Chuwen Guo ${ }^{1, *}$ and Jie Lin ${ }^{1}$ \\ 1 School of Electrical and Power Engineering, China University of Mining and Technology, \\ Xuzhou 221116, China; cumthui@126.com (H.Z.); TS17130003A3@cumt.edu.cn (J.L.) \\ 2 Xuhai College, China University of Mining and Technology, Xuzhou 221008, China \\ * Correspondence: cwguo@cumt.edu.cn; Tel.: +86-516-8359-2200
}

Received: 13 March 2019; Accepted: 18 April 2019; Published: 20 April 2019

Featured Application: The research results of this paper could be used to improve the measuring accuracy of the transit-time ultrasonic flowmeter.

\begin{abstract}
Ultrasonic wave carries the information for flowing velocity when it is propagating in flowing fluids. Flowrate can be obtained by measuring the propagation time of ultrasonic wave. The principle of transit-time ultrasonic flowmeters used today was based on that the velocity is uniform along the propagation path of the ultrasonic wave. However, it is well known that the velocity profiles in a pipe are not uniform both in laminar flow and turbulent flow. Emphasis on the effects of velocity profiles across the pipe on the propagation time of ultrasonic wave, theoretical flowrate correction factors considering the real velocity profile were proposed for laminar and turbulent flow to obtain higher accuracy. Experiment data of ultrasonic flowmeter and weighting method are compared to verify the proposed theoretical correction factors. The average relative error of proposed correction factor is determined to be $0.976 \%$ for laminar flow and $0.25 \%$ for turbulent flow.
\end{abstract}

Keywords: velocity profile; transit-time; ultrasonic flowmeter; accuracy; correction factor

\section{Introduction}

Flow measurement is necessary in engineering field for fluid metrology and process control [1,2]. A variety of flow measurement techniques were invented, such as differential pressure flowmeter [3], float flowmeter [4], volumetric flowmeter [5], electromagnetic flowmeter [6], and vortex shedding flowmeter [7]. However, the common disadvantage of these flow measurement techniques is that the fluid properties are tightly restricted due to direct contact with the flowmeters. In order to overcome the above disadvantage, non-contact ultrasonic flowmeter was developed, which is immune to temperature, causticity, and conductivity of measured fluid [8].

There is a great variety of ultrasonic flowmeters for measurement of liquid and gas flow [9-12]. Today, ultrasonic flowmeters utilize clamp-on and wetted transducers, single and multiple paths, paths on and off the diameter, passive and active principles, contra-propagating transmission, reflection (Doppler), tag correlation, vortex shedding, liquid level sensing of open channel flow or flow in partially-full conduits, and other interactions. Due to the simplicity of the measurement principle, the ultrasonic transit-time method is one of the most common techniques in industrial applications. Flowrate measurement using the ultrasonic transit-time method is based on the apparent difference of the sound velocity in the flow direction and in the opposite direction $[13,14]$. It was pointed out in reference [15] that the transit-time ultrasonic flowmeter has a relatively high uncertainty, approximately $5 \%$. The uncertainty is mainly caused by three factors, the first is the installation method of transducers; the second is the measurement of transit time, especially for pipe with a small inner diameter; the last is 
velocity distribution across the pipe [16]. A large amount of studies have been carried out to reduce the uncertainty caused by these three reasons [17-20]. For the first reason, Mahadeva et al. [21,22] improved measurement accuracy by changing the distance between transducers. Rajita et al. [23] indicated that multipath ultrasonic flowmeters can provide more accurate flow velocities than a single path. For the second reason, several research focused on developing new algorithms to obtain more accurate time differences [24]. And high time resolution electronic components have significant progress in recent years to achieve nanosecond measurement of transit time. However, there is a limited amount of information available on the effect of velocity profile on the measurement uncertainty. Looss et al. [13] have proved that the flow rate is overestimated by the effects of the assumption of uniform velocity distribution, and a correction factor is obtained empirically based on numerical simulation results for fully developed turbulence. Zheng et al. [25] gave a correction factor for the transition region with Reynolds number in the range of 2000-20000 based on experiment results by Particle Image Velocimetry (PIV) measurement. Little attention was paid to obtain correction factor for transit time ultrasonic flowmeter through theoretical analysis.

In this paper, we put emphasis on the effects of velocity profiles across the pipe on the time of ultrasonic wave propagation. Theoretical correction factors for transit-time ultrasonic flowmeters were proposed for laminar and turbulent flow to improve measurement accuracy. Flow measurement experiments were performed for laminar and turbulent flow, respectively, and experiment data of ultrasonic flowmeter and weighting method are compared to verify the proposed theoretical correction factors.

\section{Methodology}

In transit-time type ultrasonic flowmeter, the two transducers can be arranged in W-type, V-type or Z-type, as shown in Figure 1. The difference between any of the two types is the propagation distance of ultrasonic wave. The $\mathrm{W}$-type and V-type arrangement have longer distance, which will result in a longer time to be detected. So that the measurement accuracy could be improved. However, their measuring principle is the same, that is, one transducer works as transmitter and the other as a receiver, and the transmit time from one transducer to the other will reflect the flowing velocity of the fluid. Therefore, in order to make it easier for understanding, the Z-type is discussed in this paper. Additionally, the final results can be used for W-type and V-type.

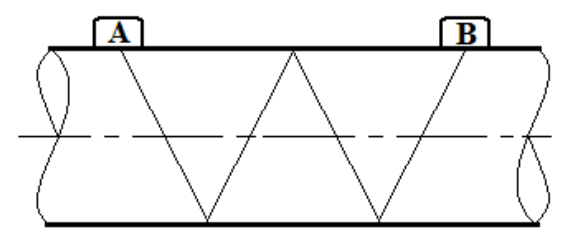

(a)

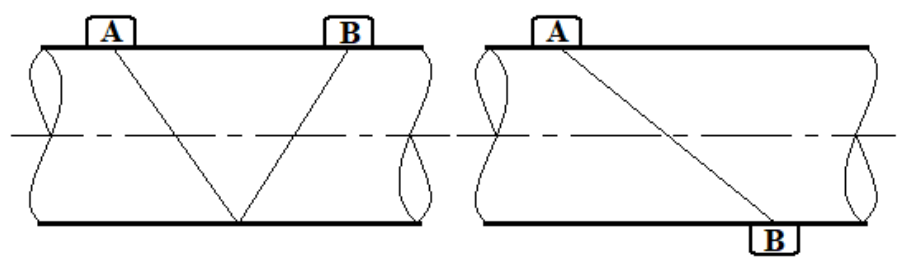

(b)

(c)

Figure 1. Arrangement of ultrasonic transducers. (a) W-type; (b) V-type; and (c) Z-type.

The basic principle of the transit-time ultrasonic flowmeter is shown in Figure 2, two ultrasonic transducers, upstream $\mathrm{P}_{1}$ and downstream $\mathrm{P}_{2}$, send and detect a short sound pulse with an oblique propagation direction (angle $\theta$ with the pipe axis). 


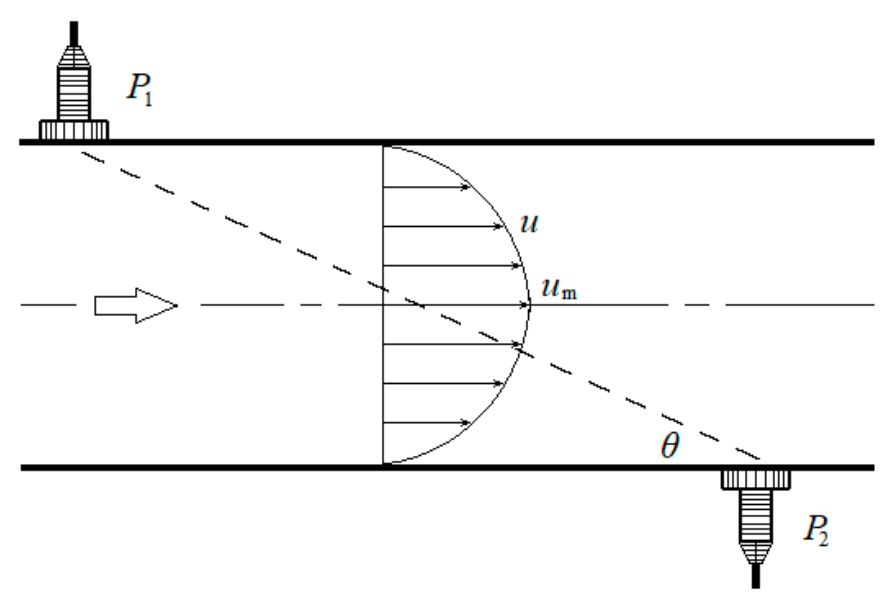

Figure 2. Principle of the transit-time ultrasonic flowmeter.

When the ultrasonic wave propagates downstream from transducer $\mathrm{P}_{1}$, its propagation speed will be coupled with the velocity projection of fluid in the direction of propagation. Therefore, the propagation time for downstream signal from $\mathrm{P}_{1}$ to $\mathrm{P}_{2}$ will be

$$
T_{1}=\frac{L}{c+u \cos \theta}
$$

where $L$ is the propagation distance of ultrasonic wave from transducer $P_{1}$ to $P_{2}, c$ is the sound speed in the fluid, $\mathrm{u}$ is the velocity of the fluid, and $\theta$ is the angle between the directions of fluid flowing and wave propagation.

Similarly, when ultrasonic wave propagates upstream from transducer $\mathrm{P}_{2}$, its propagation speed will subtract the velocity projection of fluid in the direction of propagation. Therefore, the propagation time for upstream signal from $\mathrm{P}_{2}$ to $\mathrm{P}_{1}$ will be

$$
T_{2}=\frac{L}{c-u \cos \theta}
$$

Eliminating the propagation speed of ultrasonic wave from Equations (1) and (2), the velocity of fluid can be expressed as

$$
\mathrm{u}=\frac{L}{2 \cos \theta} \cdot \frac{T_{2}-T_{1}}{T_{1} \cdot T_{2}}
$$

If the flow is axially uniform, the flowrate in the pipe can be estimated by measuring the transit times of downstream signal $T_{1}$ and upstream signal $T_{2}$, expressed as

$$
\Delta T=T_{2}-T_{1}=\frac{L}{c-u \cos \theta}-\frac{L}{c+u \cos \theta}
$$

However, the velocity distribution across the pipe is not uniform. The variation in velocity will have effects on the propagation of ultrasonic wave. Thus, Equation (4) can be used only within a very thin layer of fluid. Then,

$$
d T_{2}-d T_{1}=\frac{d L}{c-u \cos \theta}-\frac{d L}{c+u \cos \theta}
$$

where $d L$ is the propagation distance of ultrasonic wave across the thin layer.

According to geometric relation, we have

$$
\mathrm{d} L=\frac{2 d r}{\sin \theta}
$$

where, $d r$ is the thickness of the thin layer. 
Substituting Equation (6) into Equation (5), the transit times must be expressed as

$$
\Delta T=T_{2}-T_{1}=\frac{2}{\sin \theta} \int_{0}^{R}\left[\frac{1}{c-u \cos \theta}-\frac{1}{c+u \cos \theta}\right] d r
$$

where $R$ is the radius of the pipe.

Introducing a dimensionless radius $s=\frac{r}{R}$, then

$$
\Delta T=\frac{2 R}{\sin \theta} \int_{0}^{1}\left[\frac{1}{c-u \cos \theta}-\frac{1}{c+u \cos \theta}\right] d s
$$

Re-written as

$$
\Delta T=\frac{2 R}{u_{m} \sin \theta \cos \theta} \int_{0}^{1}\left[\frac{1}{K-u / u_{m}}-\frac{1}{K+u / u_{m}}\right] d s
$$

where $c$ is the sound speed; $K=\frac{c}{u_{m} \cos \theta}$.

\subsection{Laminar Flow}

For laminar flow in a pipe, the velocity profile will be

$$
u=u_{m}\left(1-\frac{r^{2}}{R^{2}}\right)=u_{m}\left(1-s^{2}\right)
$$

Substitute into Equation (9), we get

$$
\Delta T=\frac{2 R}{u_{m} \sin \theta \cos \theta} \int_{0}^{1}\left[\frac{1}{K-\left(1-s^{2}\right)}-\frac{1}{K+\left(1-s^{2}\right)}\right] d s
$$

then

$$
\Delta T=\frac{2 R}{u_{m} \sin \theta \cos \theta} \int_{0}^{1} \frac{2-2 s^{2}}{K^{2}-\left(1-s^{2}\right)^{2}} d s
$$

Because $K^{2}>>\left(1-s^{2}\right)^{2}$, then

$$
\Delta T=\frac{2 R}{u_{m} \sin \theta \cos \theta} \int_{0}^{1} \frac{2-2 s^{2}}{K^{2}} d s
$$

Finally, we have

$$
\Delta T=\frac{8 R u_{m} \cos \theta}{3 c^{2} \sin \theta}
$$

For a laminar flow, the flowrate can be expressed as $Q=\pi R^{2} \frac{u_{m}}{2}$. Then, it is easy to get the flowrate for laminar flow from Equation (14)

$$
Q=\frac{3 \pi R c^{2} \tan \theta}{16} \cdot \Delta T
$$

Equation (15) clearly indicates the effect of velocity profile on the flowrate measured.

If the effect of velocity distribution is neglected, the velocity $u$ in Equation (4) is considered to be a constant, then

$$
\Delta T=\frac{L}{c-u \cos \theta}-\frac{L}{c+u \cos \theta}=\frac{2 L u \cos \theta}{c^{2}-u^{2} \cos ^{2} \theta}
$$

Since $c^{2}>>u^{2} \cos ^{2} \theta$ and $L=\frac{2 R}{\sin \theta}$, then

$$
\Delta T=\frac{2 L u \cos \theta}{c^{2}}=\frac{4 R u \cos \theta}{c^{2} \sin \theta}
$$


Therefore, the flowrate will be

$$
Q_{0}=\pi R^{2} u=\frac{\pi R c^{2}}{4} \tan \theta \cdot \Delta T
$$

Comparing Equation (15) with (18), it is found that $Q=\frac{3}{4} Q_{0}$. That is to say, the flowrate $Q_{0}$ measured with an ultrasonic flowmeter without considering the effect of velocity profile in the pipe should be multiplied by $3 / 4$, in order to get the real flowrate.

\subsection{Turbulent Flow}

For the turbulent flow in a pipe, the velocity profile will be

$$
u=u_{m}\left(1-\frac{r}{R}\right)^{1 / n}=u_{m}(1-s)^{1 / n}
$$

where, the exponent $\mathrm{n}$ depends on Reynolds number, as shown in Table $1[19,26]$.

Table 1. Relationship between Re and $n$.

\begin{tabular}{cccccccc}
\hline $\operatorname{Re}$ & $4 \times 10^{3}$ & $2.56 \times 10^{4}$ & $1.05 \times 10^{5}$ & $2.06 \times 10^{5}$ & $3.2 \times 10^{5}$ & $3.84 \times 10^{5}$ & $4.28 \times 10^{5}$ \\
\hline $\mathrm{n}$ & 6.0 & 7.0 & 7.3 & 8.0 & 8.3 & 8.5 & 8.6 \\
\hline
\end{tabular}

Substitute Equation (19) into (9), we get

$$
\Delta T=\frac{2 R}{u_{m} \sin \theta \cos \theta} \int_{0}^{1} \frac{2(1-s)^{1 / n}}{K^{2}-(1-s)^{2 / n}} d s
$$

Because $K^{2}>>(1-s)^{2 / n}$, we finally obtain

$$
\Delta T=\frac{n}{n+1} \frac{4 R u_{m} \cos \theta}{c^{2} \sin \theta}
$$

The flowrate for turbulent flow is

$$
Q=\frac{n \pi R c^{2} \tan \theta}{4 n+2} \cdot \Delta T
$$

If the effect of velocity distribution is neglected, the velocity $u$ in Equation (9) is considered to be a constant, $u=u_{m}$, then

$$
\Delta T=\frac{2 R}{u_{m} \sin \theta \cos \theta} \int_{0}^{1}\left[\frac{1}{K-1}-\frac{1}{K+1}\right] d s=\frac{2 R}{u_{m} \sin \theta \cos \theta} \cdot \frac{2}{K^{2}-1}
$$

Because $K^{2}>>1$, we finally obtain

$$
\Delta T=\frac{4 R}{K^{2} u_{m} \sin \theta \cos \theta}=\frac{4 R u_{m} \cos \theta}{c^{2} \sin \theta}
$$

Therefore, the flowrate will be

$$
Q_{0}=\pi R^{2} u=\pi R^{2} u_{m}=\frac{\pi R c^{2}}{4} \tan \theta \cdot \Delta T
$$

Comparing Equation (22) with (25), it is found that

$$
Q=\frac{2 n}{2 n+1} \cdot Q_{0}
$$


Since the exponent $n$ depends on Reynolds number, the effect of turbulent velocity profile will also depends on the Reynolds number.

\subsection{Correction Factors for Measurement with Ultrasonic Flowmeter}

For a laminar flow, it is easy to see from Equations (15) and (18) that the laminar correction factor will be 0.75 . That is to say, the real flowrate is the result of multiplying the reading flowrate by the correction factor.

However, it is not so easy to get the final result for a turbulent flow because the correction factor is not a constant in this case. From Equation (26), the correction factor for a turbulent flow will be

$$
k_{t}=\frac{2 n}{2 n+1}
$$

The relationship between the exponent $n$ and the Reynolds number in Table 1 can be expressed as

$$
n=f(\operatorname{Re})
$$

The Reynolds number depends on the real flowrate $Q$, as follows

$$
\operatorname{Re}=\frac{2 \rho Q}{\pi \mu R}
$$

The relationship between real flowrate and the reading flowrate $Q_{0}$ is

$$
Q=k_{t} Q_{0}=\frac{2 n}{2 n+1} Q_{0}
$$

The real flowrate can be obtained from the simultaneous solution of the above Equations (28) to (30). Figure 3 gives the correction factor for a turbulent flow.

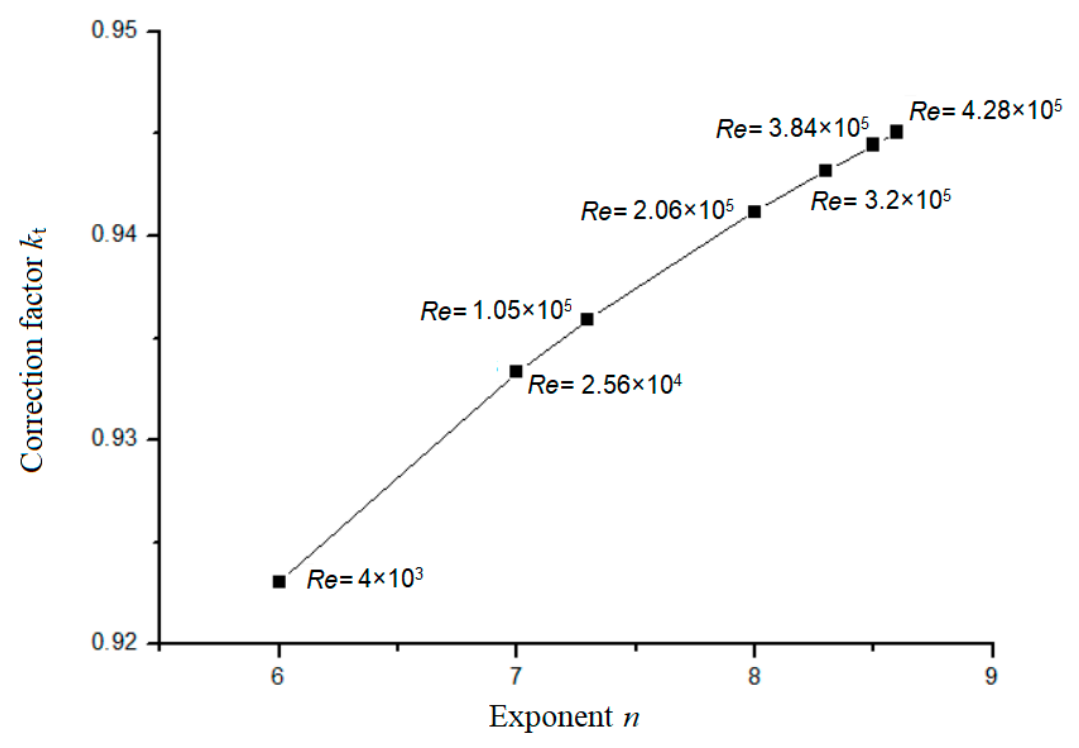

Figure 3. Correction factor for a turbulent flow.

\section{Experiment}

In order to verify the above analytical results, experiments were carried out at two testing systems, as shown in Figures 4 and 5.

Figure 4 is a Reynolds' apparatus, with which accurate results can be obtained when the Reynolds number is low. In order to keep the head of the upper tank be a constant, a stabilizing plate and an 
overflow plate are set. The head is $0.4 \mathrm{~m}$. The experimental tube is made of organic glass with an inner diameter of $14 \mathrm{~mm}$. Therefore, the maximum Reynolds number with this apparatus will be about $1.7 \times 10^{5}$.

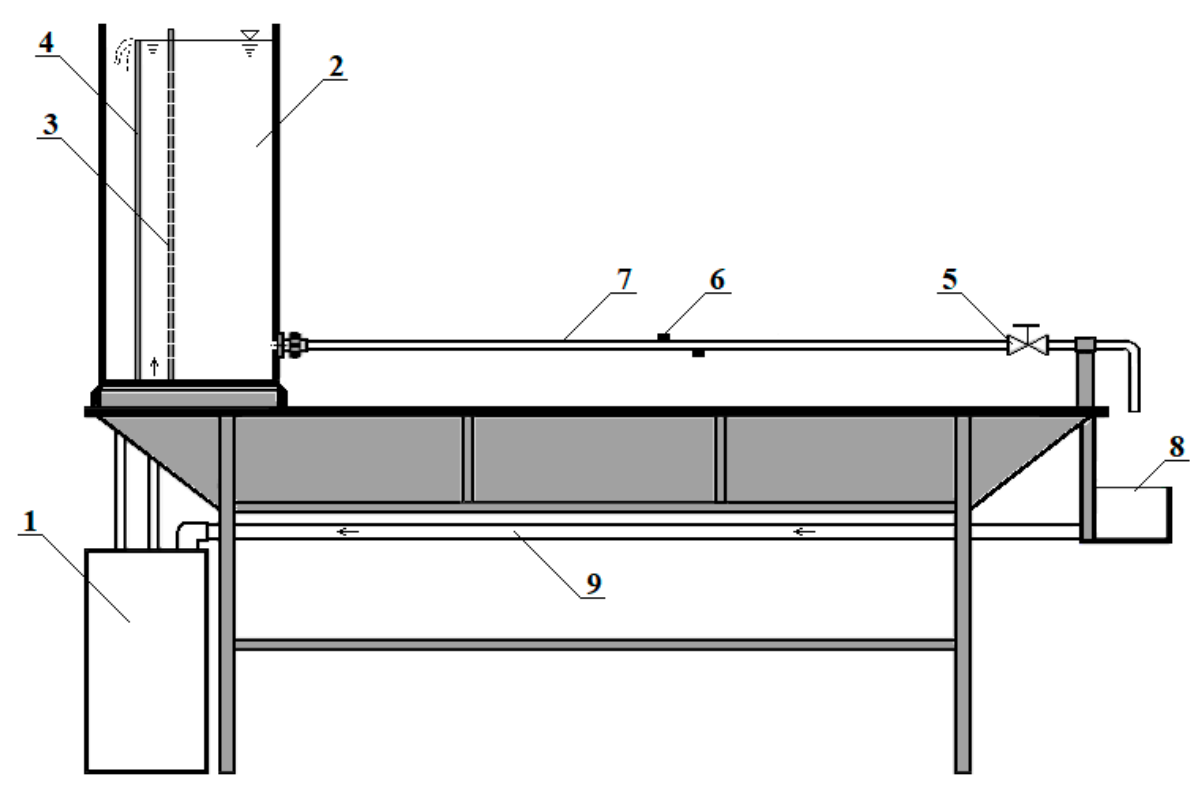

Figure 4. The Reynolds' apparatus. 1-water tank with pump; 2-tank with constant head; 3-stabilizing plate; 4-overflow plate; 5-regulating valve; 6-ultrasonic transducers; 7-experimental tube; 8-small container; and 9-return tube.

Since the Reynolds' apparatus could not reach a higher Reynolds number, a performance testing system for centrifugal pump is used, as shown in Figure 5. The rated flowrate of the centrifugal pump in the system is $65 \mathrm{~m}^{3} / \mathrm{h}$, and the inner diameter of the experimental pipe is $50.8 \mathrm{~mm}$. The maximum Reynolds number with this system can be as high as $4.24 \times 10^{5}$.

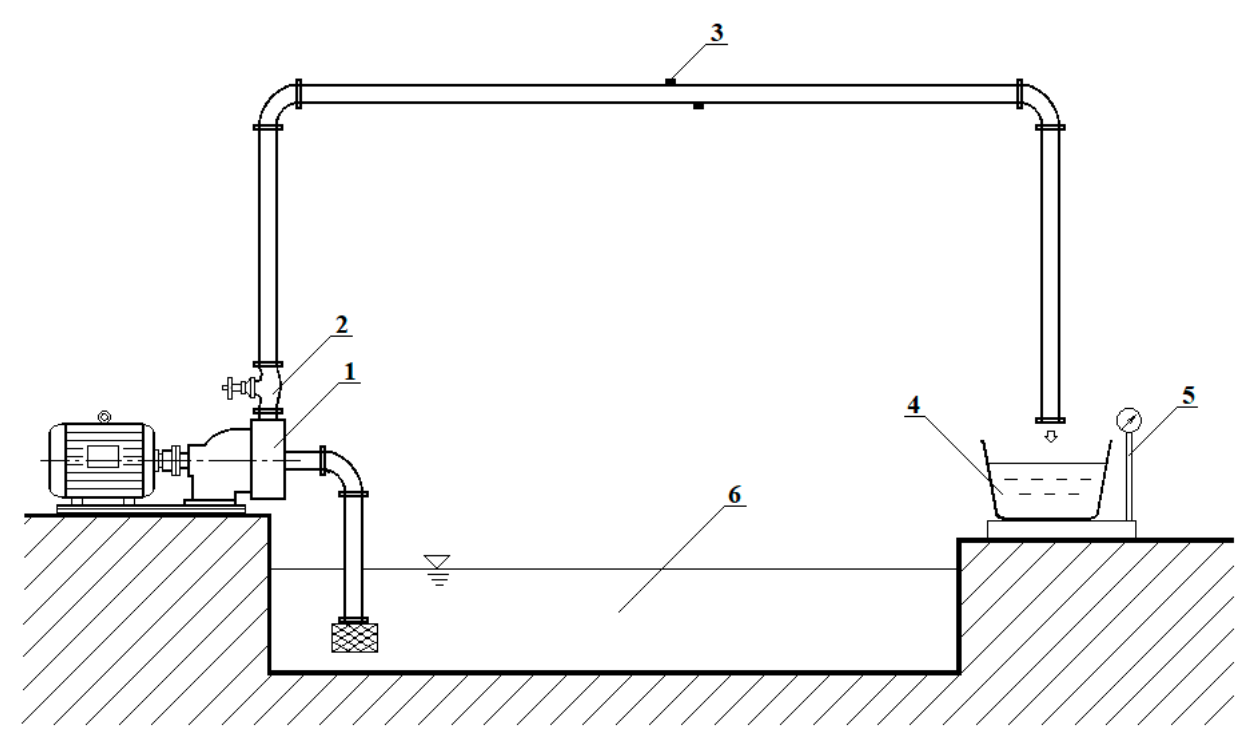

Figure 5. The performance testing system for centrifugal pumps. 1-centrifugal pump; 2-regulating valve; 3-ultrasonic transducers; 4-water tank; 5-electronic scale; 6-water tank.

The Reynolds number can be easily adjusted by the regulating valves in both systems. Flowrate was measured by a TDS-100H portable ultrasonic flowmeter and by the weight of water flowing out of the pipe within a certain time interval. 


\section{Results}

\subsection{Verification}

Table 2 gives the results of flowrate measurement at the Reynolds' apparatus. The flowrate $Q_{1}$ is measured by the ultrasonic flowmeter, while $Q_{2}$ is measured by the weight discharged within a certain period of time. The flowrate ratio $Q_{2}: Q_{1}$ is the measured correction factor. The relative error $\left(\delta_{1}\right)$ defined in Equation (31), is used to evaluate the difference between theoretical correction factor and measured data, where $\mathrm{k}$ indicates the theoretical correction factor.

$$
\delta_{1}=\left|\frac{k-\beta}{k}\right| \times 100 \%
$$

Table 2. Results of flowrate measured at the Reynolds' apparatus.

\begin{tabular}{|c|c|c|c|c|c|c|c|c|c|}
\hline \multirow[b]{2}{*}{ No. } & \multicolumn{2}{|c|}{ Ultrasonic Flowmeter } & \multicolumn{5}{|c|}{ Weighing Method } & \multirow{2}{*}{$\begin{array}{c}\text { Flowrate } \\
\text { Ratio } \\
\beta=Q_{2}: Q_{1}\end{array}$} & \multirow[b]{2}{*}{$\delta_{1}(\%)$} \\
\hline & $\begin{array}{c}\Delta T \times 10^{9} \\
\quad(\mathrm{~s})\end{array}$ & $\begin{array}{c}\text { Flowrate } \\
Q_{1} \times 10^{5} \\
\left(\mathrm{~m}^{3} / \mathrm{s}\right)\end{array}$ & $\begin{array}{l}\text { Time } \\
\text { (s) }\end{array}$ & $\begin{array}{l}\text { Mass } \\
(\mathrm{kg})\end{array}$ & $\begin{array}{c}\text { Flowrate } \\
Q_{2} \times 10^{5} \\
\left(\mathrm{~m}^{3} / \mathrm{s}\right)\end{array}$ & $\begin{array}{c}\text { Velocity } \\
(\mathrm{m} / \mathrm{s})\end{array}$ & $\operatorname{Re}$ & & \\
\hline 1 & 0.378 & 0.970 & 60 & 0.430 & 0.717 & 0.047 & 652 & 0.739 & 1.443 \\
\hline 2 & 0.462 & 1.185 & 60 & 0.524 & 0.873 & 0.057 & 795 & 0.737 & 1.772 \\
\hline 3 & 0.632 & 1.622 & 60 & 0.721 & 1.202 & 0.078 & 1094 & 0.741 & 1.192 \\
\hline 4 & 1.002 & 2.572 & 50 & 0.965 & 1.930 & 0.125 & 1757 & 0.751 & 0.052 \\
\hline 5 & 1.121 & 2.877 & 50 & 1.073 & 2.147 & 0.140 & 1954 & 0.746 & 0.498 \\
\hline 6 & 1.310 & 3.363 & 40 & 1.005 & 2.512 & 0.163 & 2286 & 0.747 & 0.406 \\
\hline 7 & 1.317 & 3.380 & 40 & 1.019 & 2.548 & 0.166 & 2318 & 0.754 & 0.513 \\
\hline 8 & 1.553 & 3.987 & 40 & 1.219 & 3.048 & 0.198 & 2774 & 0.764 & 1.931 \\
\hline
\end{tabular}

From Equations (15) and (18), it is clearly indicated that the theoretical correction factor for laminar flow is 0.75 . It can be seen from Table 2 that the flowrate ratios $(\beta)$ are in range of 0.737 to 0.764 , the average value of $\beta$ is 0.747 . The average relative error is $0.976 \%$, and the maximum relative error is $1.931 \%$, which is in good agreement with the experiment result. The last line in Table 2 is in the transition zone from laminar flow to turbulent flow, and the correction factor is a little bit larger than 0.75 , which is caused by the gradual changing of velocity profile from laminar flow to turbulent flow.

Table 3 gives the results of flowrate measured at the performance testing system for centrifugal pumps. The Reynolds numbers are from 4311 to 422102 . The theoretical turbulent flow correction factor $\left(k_{t}\right)$ is calculated by Equation (27). The average relative error is $0.25 \%$ and maximum error is $1.178 \%$. Therefore, the theoretical correction factor is reliable.

Table 3. Results of flowrate measurement at the performance testing system for centrifugal pumps.

\begin{tabular}{|c|c|c|c|c|c|c|c|c|c|c|c|}
\hline \multirow[b]{2}{*}{ No. } & \multicolumn{2}{|c|}{ Ultrasonic Flowmeter } & \multicolumn{6}{|c|}{ Weighing Method } & \multirow{2}{*}{$\begin{array}{c}\text { Flowrate } \\
\text { Ratio } \\
\beta=Q_{2}: Q_{1}\end{array}$} & \multirow[b]{2}{*}{$k_{t}$} & \multirow[b]{2}{*}{$\delta_{2}(\%)$} \\
\hline & $\begin{array}{c}\Delta T \times 10^{9} \\
(\mathrm{~s})\end{array}$ & $\begin{array}{c}\text { Flowrate } \\
Q_{1} \times 10^{5} \\
\left(\mathrm{~m}^{3} / \mathrm{s}\right)\end{array}$ & $\begin{array}{l}\text { Time } \\
\text { (s) }\end{array}$ & $\begin{array}{c}\text { Mass } \\
(\mathrm{kg})\end{array}$ & $\begin{array}{c}\text { Flowrate } \\
Q_{2} \times 10^{5} \\
\left(\mathrm{~m}^{3} / \mathrm{s}\right)\end{array}$ & $\begin{array}{c}\text { Velocity } \\
(\mathrm{m} / \mathrm{s})\end{array}$ & $\operatorname{Re}$ & $n$ & & & \\
\hline 1 & 7.270 & 0.186 & 60 & 10.314 & 0.172 & 0.085 & 4311 & 6 & 0.925 & 0.923 & 0.216 \\
\hline 2 & 17.714 & 0.454 & 40 & 16.939 & 0.424 & 0.209 & 10619 & 6 & 0.934 & 0.923 & 1.178 \\
\hline 3 & 36.956 & 0.948 & 30 & 26.438 & 0.881 & 0.435 & 22099 & 6 & 0.929 & 0.923 & 0.646 \\
\hline 4 & 43.889 & 1.125 & 20 & 20.984 & 1.049 & 0.518 & 26310 & 7 & 0.932 & 0.933 & 0.107 \\
\hline 5 & 76.663 & 1.966 & 15 & 27.566 & 1.838 & 0.907 & 46084 & 7 & 0.935 & 0.933 & 0.214 \\
\hline 6 & 112.156 & 2.876 & 15 & 40.387 & 2.693 & 1.329 & 67518 & 7 & 0.936 & 0.933 & 0.321 \\
\hline 7 & 143.424 & 3.677 & 10 & 34.384 & 3.438 & 1.697 & 86223 & 7 & 0.935 & 0.933 & 0.214 \\
\hline 8 & 171.690 & 4.402 & 10 & 41.125 & 4.113 & 2.030 & 103127 & 7.3 & 0.934 & 0.936 & 0.214 \\
\hline 9 & 244.767 & 6.276 & 10 & 58.683 & 5.868 & 2.897 & 147156 & 7.3 & 0.935 & 0.936 & 0.110 \\
\hline 10 & 312.871 & 8.022 & 10 & 75.124 & 7.513 & 3.708 & 188385 & 7.3 & 0.937 & 0.936 & 0.107 \\
\hline 11 & 341.571 & 8.758 & 8 & 66.056 & 8.257 & 4.076 & 207057 & 8 & 0.943 & 0.941 & 0.212 \\
\hline 12 & 440.921 & 11.305 & 8 & 85.452 & 10.681 & 5.273 & 267854 & 8 & 0.945 & 0.941 & 0.423 \\
\hline 13 & 532.958 & 13.664 & 7 & 90.218 & 12.888 & 6.362 & 323193 & 8.3 & 0.943 & 0.943 & 0.000 \\
\hline 14 & 597.541 & 15.320 & 5 & 72.367 & 14.473 & 7.145 & 362942 & 8.3 & 0.945 & 0.943 & 0.212 \\
\hline
\end{tabular}


Table 3. Cont.

\begin{tabular}{|c|c|c|c|c|c|c|c|c|c|c|c|}
\hline \multirow[b]{2}{*}{ No. } & \multicolumn{2}{|c|}{ Ultrasonic Flowmeter } & \multicolumn{6}{|c|}{ Weighing Method } & \multirow{2}{*}{$\begin{array}{c}\text { Flowrate } \\
\text { Ratio } \beta \\
=Q_{2}: Q_{1}\end{array}$} & \multirow[b]{2}{*}{$k_{t}$} & \multirow[b]{2}{*}{$\delta_{2}(\%)$} \\
\hline & $\begin{array}{c}\Delta T \times 10^{9} \\
\quad(\mathrm{~s})\end{array}$ & $\begin{array}{c}\text { Flowrate } \\
Q_{1} \times 10^{5} \\
\left(\mathrm{~m}^{3} / \mathrm{s}\right)\end{array}$ & $\begin{array}{l}\text { Time } \\
\text { (s) }\end{array}$ & $\begin{array}{c}\text { Mass } \\
\text { (kg) }\end{array}$ & $\begin{array}{c}\text { Flowrate } \\
Q_{2} \times 10^{5} \\
\left(\mathrm{~m}^{3} / \mathrm{s}\right)\end{array}$ & $\begin{array}{c}\text { Velocity } \\
(\mathrm{m} / \mathrm{s})\end{array}$ & $\operatorname{Re}$ & $n$ & & & \\
\hline 15 & 629.177 & 16.131 & 5 & 76.218 & 15.244 & 7.525 & 382256 & 8.5 & 0.945 & 0.944 & 0.106 \\
\hline 16 & 662.113 & 16.976 & 5 & 80.136 & 16.027 & 7.912 & 401906 & 8.5 & 0.944 & 0.944 & 0.000 \\
\hline 17 & 694.919 & 17.817 & 5 & 84.163 & 16.833 & 8.309 & 422102 & 8.6 & 0.945 & 0.945 & 0.000 \\
\hline
\end{tabular}

\subsection{Uncertainty Analysis}

The flowrate obtained by the weighing method is regarded as the standard to evaluate the measurement results of the ultrasonic flowmeter. Therefore, the experiment uncertainty of weighting method is analyzed and results for laminar and turbulent flow are shown in Tables 4 and 5, respectively. Collected time is controlled by an electronic timer, the uncertainty of time is $10 \mathrm{~ms}$. Collected mass is weighed by an electronic scale, the uncertainty of mass is $1 \mathrm{~g}$. The standard relative uncertainty of time is from $0.017 \%$ to $0.200 \%$; from $0.001 \%$ to $0.233 \%$ of mass. The combined uncertainty is from $0.019 \%$ to $0.233 \%$. The expanded uncertainty has been reported at $k=2$, which from $0.039 \%$ to $0.466 \%$.

Table 4. Experiment uncertainty for laminar flow.

\begin{tabular}{|c|c|c|c|c|c|c|}
\hline \multirow[b]{2}{*}{ No. } & \multicolumn{2}{|c|}{ Collected Mass } & \multicolumn{2}{|c|}{ Collected Time } & \multirow{2}{*}{$\begin{array}{c}\text { Combined } \\
\text { Uncertainty } \\
\left(\mu_{c}\right)(\%)\end{array}$} & \multirow{2}{*}{$\begin{array}{c}\text { Expanded } \\
\text { Uncertainty } \\
(U)(\%)\end{array}$} \\
\hline & $\begin{array}{c}\text { Estimate } \\
(M)(\mathrm{kg})\end{array}$ & $\begin{array}{l}\text { Uncertainty } \\
\left(\mu_{M}\right)(\%)\end{array}$ & $\begin{array}{c}\text { Estimate } \\
(\Delta t)(\mathrm{s})\end{array}$ & $\begin{array}{c}\text { Uncertainty } \\
\left(\mu_{\Delta t}\right)(\%)\end{array}$ & & \\
\hline 1 & 0.43 & 0.233 & 60 & 0.017 & 0.233 & 0.466 \\
\hline 2 & 0.524 & 0.191 & 60 & 0.017 & 0.192 & 0.383 \\
\hline 3 & 0.721 & 0.139 & 60 & 0.017 & 0.140 & 0.279 \\
\hline 4 & 0.965 & 0.104 & 50 & 0.020 & 0.106 & 0.211 \\
\hline 5 & 1.073 & 0.093 & 50 & 0.020 & 0.095 & 0.191 \\
\hline 6 & 1.005 & 0.100 & 40 & 0.025 & 0.103 & 0.205 \\
\hline 7 & 1.019 & 0.098 & 40 & 0.025 & 0.101 & 0.203 \\
\hline 8 & 1.219 & 0.082 & 40 & 0.025 & 0.086 & 0.172 \\
\hline
\end{tabular}

Table 5. Experiment uncertainty for turbulent flow.

\begin{tabular}{|c|c|c|c|c|c|c|}
\hline \multirow{2}{*}{ No. } & \multicolumn{2}{|c|}{ Collected Mass } & \multicolumn{2}{|c|}{ Collected Time } & \multirow{2}{*}{$\begin{array}{c}\text { Combined } \\
\text { Uncertainty } \\
\left(\mu_{\mathrm{c}}\right)(\%)\end{array}$} & \multirow{2}{*}{$\begin{array}{c}\text { Expanded } \\
\text { Uncertainty } \\
(U)(\%)\end{array}$} \\
\hline & $\begin{array}{l}\text { Estimate } \\
(M)(\mathrm{kg})\end{array}$ & $\begin{array}{c}\text { Uncertainty } \\
\left(\mu_{M}\right)(\%)\end{array}$ & $\begin{array}{c}\text { Estimate } \\
(\Delta t)(\mathrm{s})\end{array}$ & $\begin{array}{c}\text { Uncertainty } \\
\left(\mu_{\Delta t}\right)(\%)\end{array}$ & & \\
\hline 1 & 10.314 & 0.010 & 60 & 0.017 & 0.019 & 0.039 \\
\hline 2 & 16.939 & 0.006 & 40 & 0.025 & 0.026 & 0.051 \\
\hline 3 & 26.438 & 0.004 & 30 & 0.033 & 0.034 & 0.067 \\
\hline 4 & 20.984 & 0.005 & 20 & 0.050 & 0.050 & 0.100 \\
\hline 5 & 27.566 & 0.004 & 15 & 0.067 & 0.067 & 0.134 \\
\hline 6 & 40.387 & 0.002 & 15 & 0.067 & 0.067 & 0.133 \\
\hline 7 & 34.384 & 0.003 & 10 & 0.100 & 0.100 & 0.200 \\
\hline 8 & 41.125 & 0.002 & 10 & 0.100 & 0.100 & 0.200 \\
\hline 9 & 58.683 & 0.002 & 10 & 0.100 & 0.100 & 0.200 \\
\hline 10 & 75.124 & 0.001 & 10 & 0.100 & 0.100 & 0.200 \\
\hline 11 & 66.056 & 0.002 & 8 & 0.125 & 0.125 & 0.250 \\
\hline 12 & 85.452 & 0.001 & 8 & 0.125 & 0.125 & 0.250 \\
\hline 13 & 90.218 & 0.001 & 7 & 0.143 & 0.143 & 0.286 \\
\hline 14 & 72.367 & 0.001 & 5 & 0.200 & 0.200 & 0.400 \\
\hline 15 & 76.218 & 0.001 & 5 & 0.200 & 0.200 & 0.400 \\
\hline 16 & 80.136 & 0.001 & 5 & 0.200 & 0.200 & 0.400 \\
\hline 17 & 84.163 & 0.001 & 5 & 0.200 & 0.200 & 0.400 \\
\hline
\end{tabular}




\section{Conclusions}

The effect of velocity profiles across the pipe on the propagation time of ultrasonic wave is considered for transit-time ultrasonic flowmeters. Theoretical correction factors were proposed to improve measurement accuracy. For laminar flow, the correction factor is a constant of 0.75 . For turbulent flow, the correction factor varies with Reynolds number, show as Equation (27). Flow measurement experiments were performed for laminar and turbulent flow respectively, and experiment results showed that the proposed correction factors agree well with measured correction factors. The average relative error is determined to be $0.976 \%$ for laminar flow and $0.25 \%$ for turbulent flow.

Author Contributions: Conceptualization, C.G.; Data curation, H.Z.; Formal analysis, H.Z.; Funding acquisition, C.G.; Investigation, H.Z.; Methodology, C.G.; Resources, J.L.; Software, J.L.; Writing-original draft, H.Z.; Writing-review \& editing, C.G.

Funding: This research was funded by the Fundamental Research Funds for the Central Universities, grant number 2017XKZD02.

Acknowledgments: The authors are very grateful to Dr. Wang Fengchao for his help in the experiments.

Conflicts of Interest: The authors declare no conflict of interest.

\section{References}

1. Ferrari, A.; Pizzo, P.; Rundo, M. Modelling and experimental studies on a proportional valve using an innovative dynamic flow-rate measurement in fluid power systems. Proc. Inst. Mech. Eng. Part C: J. Mech. Eng. Sci. 2018, 232, 2404-2418. [CrossRef]

2. Sun, Y.; Zhang, T.; Zheng, D. New Analysis Scheme of Flow-Acoustic Coupling for Gas Ultrasonic Flowmeter with Vortex near the Transducer. Sensors 2018, 18, 1151.

3. Grände, P.O.; Borgström, P. An electromic differential pressure flowmeter and a resistance meter for continuous measurement of vascular resistance. Acta Physiol. Scand. 2010, 102, 224-230. [CrossRef] [PubMed]

4. Bückle, U.; Durst, F.; Howe, B.; Melling, A. Investigation of a floating element flowmeter. Flow Meas. Instrum. 1992, 3, 215-225. [CrossRef]

5. Gibson, W.G.; Cobbold, R.S.; Johnston, K.W. Principles and design feasibility of a Doppler ultrasound intravascular volumetric flowmeter. IEEE Trans. Bio.-Med. Eng. 1994, 41, 898. [CrossRef] [PubMed]

6. Bevir, M.K. The theory of induced voltage electromagnetic flowmeter. J. Fluid Mech. 2006, 43, 577-590. [CrossRef]

7. Pasquale, G.D.; Graziani, S.; Pollicino, A.; Strazzeri, S. A vortex-shedding flowmeter based on IPMCs. Smart Mater. Struct. 2016, 25, 015011. [CrossRef]

8. Lynnworth, L.C.; Liu, Y. Ultrasonic flowmeters: Half-century progress report, 1955-2005. Ultrasonics 2006, 44, E1371-E1378. [CrossRef]

9. Chhantyal, K.; Jondahl, M.H.; Viumdal, H.; Mylvaganam, S. Upstream Ultrasonic Level Based Soft Sensing of Volumetric Flow of Non-Newtonian Fluids in Open Venturi Channels. IEEE Sens. J. 2018, 18, 5002-5013. [CrossRef]

10. Jiang, Y.D.; Wang, B.L.; Li, X.; Liu, D.D.; Wang, Y.Q.; Huang, Z.Y. A Model-Based Hybrid Ultrasonic Gas Flowmeter. IEEE Sens. J. 2018, 18, 4443-4452. [CrossRef]

11. Liu, B.; Xu, K.J.; Mu, L.B.; Tian, L. Echo energy integral based signal processing method for ultrasonic gas flow meter. Sens. Actuat. A-Phys. 2018, 277, 181-189. [CrossRef]

12. Raine, A.B.; Aslam, N.; Underwood, C.P.; Danaher, S. Development of an Ultrasonic Airflow Measurement Device for Ducted Air. Sensors 2015, 15, 10705-10722. [CrossRef] [PubMed]

13. Iooss, B.; Lhuillier, C.; Jeanneau, H. Numerical simulation of transit-time ultrasonic flowmeters: Uncertainties due to flow profile and fluid turbulence. Ultrasonics 2002, 40, 1009-1015. [CrossRef]

14. Mandard, E.; Kouame, D.; Battault, R.; Remenieras, J.P.; Patat, F. Transit time ultrasonic flowmeter: Velocity profile estimation. Ultrason 2005, 2, 763-766.

15. Sanderson, M.L.; Yeung, H. Guidelines for the use of ultrasonic non-invasive metering techniques. Flow Meas. Instrum. 2002, 13, 125-142. [CrossRef] 
16. Jaiswal, S.K.; Yadav, S.; Agarwal, R. Multiple Weighing Based Method for Realizing Flow. Mapan 2015, 30 , 119-123. [CrossRef]

17. Willatzen, M. Perturbation theory applied to sound propagation in flowing media confined by a cylindrical waveguide. J. Acoust. Soc. Am. 2001, 109, 102-107. [CrossRef] [PubMed]

18. Willatzen, M.; Kamath, H. Nonlinearities in ultrasonic flow measurement. Flow Meas. Instrum. 2008, 19, 79-84. [CrossRef]

19. Willatzen, M. Ultrasonic flowmeters: Temperature gradients and transducer geometry effects. Ultrasonics 2003, 41, 105-114. [CrossRef]

20. Dadashnialehi, A.; Moshiri, B. Online monitoring of transit-time ultrasonic flowmeters based on fusion of optical observation. Measurement 2011, 44, 1028-1037. [CrossRef]

21. Mahadeva, D.V.; Baker, R.C.; Woodhouse, J. Further Studies of the Accuracy of Clamp-on Transit-Time Ultrasonic Flowmeters for Liquids. IEEE Trans. Instrum. Meas. 2009, 58, 1602-1609. [CrossRef]

22. Mahadeva, D.V.; Baker, R.C.; Woodhouse, J. Studies of the Accuracy of Clamp-on Transit Time Ultrasonic Flowmeters. In Proceedings of the 2008 IEEE Instrumentation and Measurement Technology Conference, Victoria, Canada, 12-15 May 2008; pp. 969-973.

23. Rajita, G.; Mandal, N. Review on transit time ultrasonic flowmeter. In Proceedings of the International Conference on Control, Kolkata, India, 28-30 January 2016.

24. Wang, X.F.; Tang, Z.A. Note: Ultrasonic gas flowmeter based on optimized time-of-flight algorithms. Rev. Sci. Instrum. 2011, 82, 1371-1584. [CrossRef] [PubMed]

25. Liu, Z.G.; Du, G.S.; Shao, Z.F.; He, Q.R.; Zhou, C.L. Measurement of transitional flow in pipes using ultrasonic flowmeters. Fluid Dyn. Res. 2014, 46, 055501.

26. Xiong, Y.T.; Su, Z.D.; Lin, J.D.; Zhang, Y.C. Calibration of large diameter gas flowmeter by the corresponding velocity distribution equation. J. China Univ. Metrol. 2011, 22, 25-29.

(C) 2019 by the authors. Licensee MDPI, Basel, Switzerland. This article is an open access article distributed under the terms and conditions of the Creative Commons Attribution (CC BY) license (http://creativecommons.org/licenses/by/4.0/). 